\title{
Neurologic Signs Predict Periventricular White Matter Lesions on MRI
}

\author{
Charles J. Bae, Jonathan H. Pincus
}

\begin{abstract}
Objective: Periventricular white matter disease (PVWD) is associated with abnormalities on tests that involve complex cognitive processes, along with an increased risk of cerebrovascular events which are associated with significant morbidity in older patients. This study investigates whether the neurological examination can predict the presence of PVWD on magnetic resonance imaging (MRI). No prior studies have assessed whether the neurological examination can predict the presence of PVWD on MRI. Methods: A focused neurological examination was performed on a random selection of patients referred for a MRI of the brain. Staff neuroradiologists who were blinded to the results of the physical examination independently read the MRI scans. The MRI interpretations were divided into four categories based on the degree of PVWD: none, mild, moderate, severe. Results: Twenty-three subjects had some degree of PVWD, while 25 subjects had none. The total number of neurologic signs correlated significantly with the severity of PVWD even when adjusting for the effect of age (rho=0.67, $\mathrm{p}<0.001$ ). Ninety-one percent of subjects with PVWD had three or more abnormal signs, while $76 \%$ of subjects without PVWD had fewer than three. Abnormalities with the three step motor sequencing and horizontal visual tracking tests were maximally predictive of PVWD. One or both of these tests were abnormal in $96 \%$ of subjects with PVWD, while $64 \%$ of subjects without PVWD had no problems with either test. Conclusion: Simple neurologic tests can predict the presence or absence of PVWD on MRI.
\end{abstract}

RÉSUMÉ: Des signes neurologiques prédisent les lésions périventriculaires de la substance blanche à l'imagerie parrésonance magnétique. Objectif: La maladie périventriculaire de la substance blanche (MPVSB) est associée à des anomalies des épreuves qui impliquent des processus cognitifs complexes ainsi qu'un risque accru d'événements vasculaires cérébraux comportent une morbidité importante chez les patients âgés. Le but de cette étude était de déterminer si l'examen neurologique peut prédire la présence de MPVSB à l'imagerie par résonance magnétique (IRM), ce qu'aucune étude antérieure n'a évalué. Méthodes: Un examen neurologique ciblé a été effectué chez des patients choisis au hasard, référés pour IRM cérébrale. Les neuroradiologistes du service interprétaient les examens de façon indépendante, à l'insu des résultats de l'examen physique. Les interprétations étaient divisées en quatre catégories, selon le degré de MPVSB: aucune, légère, modérée, sévère. Résultats: Vingttrois patients avaient une MPVSB, alors que 25 n'en avaient pas. La corrélation entre le nombre total de signes neurologiques et la sévérité de la MPVSB était au-delà du seuil de significativité, même après ajustement pour l'effet de l'âge (rho $=0,67 ; p<0,001)$. Quatre-vingt-dix pour cent des patients ayant une MPVSB avaient trois signes anormaux ou plus, alors que $76 \%$ des patients sans MPVSB en avaient moins de trois. Les épreuves qui prédisaient le mieux la MPVSB étaient le three step motor sequencing test et le horizontal visual tracking test. Un ou les deux tests étaient anormaux chez $96 \%$ des patients atteints de MPVSB, alors qu'ils étaient normaux chez $64 \%$ des patients sans MPVSB. Conclusion: Des épreuves neurologiques simples peuvent prédire la présence ou l'absence de la MPVSB à l'IRM.

Can. J. Neurol. Sci. 2004; 31: 242-247

Periventricular white matter disease (PVWD) correlates with abnormalities on neuropsychological tests that assess complex cognitive processes ${ }^{1}$ and the severity of PVWD correlates with deficits in attention, visual recognition and cognitive speed. ${ }^{2}$ In Alzheimer's disease, PVWD correlates with the severity of dementia. ${ }^{3}$ Certain deficits found on language and memory tests can predict whether PVWD is present. ${ }^{4}$

No prior studies have assessed whether the neurological examination, in patients who lack focal or lateralizing signs, can predict the degree of PVWD seen on MRI. This study investigated the relationship between commonly tested

From the Cleveland Clinic Foundation, Cleveland OH (CJB); Veterans Administration Medical Center, Washington DC (JHP); USA

ReCeived March 3, 2003. ACCEPTEDinfinalform SePtember 11, 2003.

Reprint requests to: Charles J. Bae, Cleveland Clinic Foundation, Department of Neurology-S51, 9500 Euclid Avenue, Cleveland, OH 44195 USA. 
"cortical" neurologic signs and the presence and severity of PVWD as seen on MRI. The term "cortical signs" was used by Jenkyn et al to characterize the tests they performed, correlating them with the Halstead-Reitan battery ${ }^{5}$ and age. ${ }^{6}$ Similar tests were utilized in this study and we retained the term, though we consider the signs to indicate subcortical dysfunction as well.

\section{Methods}

From August 1997 to October 1997, 63 subjects (35 female, 28 males) who had MRI scanning of the brain at the Georgetown University Hospital were randomly selected without regard to the reason for the MRI in this blinded prospective study. Informed consent was obtained from all subjects.

Six subjects with lateralizing signs (i.e. unilateral grasp reflex) and nine patients with a history of surgical intervention secondary to malignancy or aneurysm were excluded. Fortyeight subjects without focal or lateralizing neurological symptoms or signs (21 males, 27 females) were included in the study. The mean age of the subjects was 52.1 years (range 10-90 years).

One of the authors $(\mathrm{CB})$ performed a neurologic exam on all subjects prior to imaging. The exam consisted of 17 neurologic signs (Table 1). A detailed description of the following tests was described by Jenkyn et al: ${ }^{5}$ nuchocephalic reflex, glabellar blink, horizontal visual tracking, snout reflex, suck reflex, grasp reflex, palmomental reflex, paratonia of arms and legs, impersistence of lateral gaze, impersistence of eye closure/tongue protrusion, extinction of double simultaneous stimulation, spelling "world" forwards and backwards. Luria ${ }^{7}$ described the tests we used to detect abnormalities on three step motor sequencing and palm/fist alteration. Borkowski et $\mathrm{al}^{8}$ described how to test word fluency.

All scans were performed on a Siemens Vision 1.5T system (Erlangen, Germany). Each subject had at a minimum T1 axial and sagittal, T2 and FLAIR axial sequences taken. The majority of subjects also received gadolinium contrast and had $\mathrm{T} 1$ in two planes along with axial and sagittal sequences.

The MRI scans were read by one of three staff neuroradiologists who were blinded to the results of the focused neurological exam. The severity of PVWD was used to assess the severity of leukoaraiosis. Periventricular white matter disease seen on MRI was divided into one of four categories based on a scale as follows: 1) no PVWD, 2) mild PVWD indicating the presence of small, punctate areas of hyperintensity, 3) moderate PVWD indicating the presence of a thin confluent lining of hyperintensity around the ventricles along with small, punctate foci, and 4) severe PVWD indicating the presence of large confluent areas of hyperintensity. The grading scale used is similar to one used by Ylikoski. ${ }^{9}$

\section{Statistical analysis}

A stepwise multiple regression analysis was used to determine which of the neurological signs contributed the most variance in predicting PVWD. All signs were included as independent variables. The severity of PVWD was the dependent variable. Age was used as a covariant. Signs which were determined in the multiple regression analysis to contribute to

\section{Table 1: Neurologic tests used in this study}

1. Nuchocephalic reflex

2. Glabellar blink

3. Visual tracking

4. Snout reflex

5. Suck reflex

6. Grasp reflex

7. Palmomental reflex

8. Paratonia of arms

9. Paratonia of legs

10. Lateral gaze impersistence

11. Eye closure impersistence

12. Tongue protusion impersistence

13. Double simultaneous stimulation

14. Spelling world

15. Three step motor sequence

16. Palm/fist alternating reciprocal

17. Word fluency
- The shoulders of a patient whose eyes were closed were turned quickly to the left and right, while noting the position of the head.

- The patient was instructed to look at a point across the room, while the forehead was tapped by the examiner 8-10 times while standing outside of the visual field.

- While keeping the head still, the patient was asked to follow the examiner's finger as it was moved between two extremes of horizontal gaze.

- The examiner pressed and withdrew the middle phalange of the index finger against the patient's closed lips.

- The examiner placed the knuckle of a flexed index finger between the patient's lips.

- The examiner stroked each palmar surface of the patient's hands with and without distraction.

- The examiner firmly stroked each thenar eminence of the patient's hands with a thumbnail.

- The examiner held up an arm of the patient, then dropped the extremity.

- The examiner held up a leg of the patient, then dropped the extremity.

- The patient was asked to look at the examiner's finger held at 45 degrees from the horizontal plane for 30 seconds.

- $\quad$ Patients were asked to close their eyes for 10 seconds.

- Patients were asked to stick out their tongues for 10 seconds.

- The examiner touched the ipsilateral hand and cheek on patients who had closed their eyes, while being asked where they were being touched.

- The patient was asked to spell world forwards and backwards.

- The patient was asked to perform three consecutive changes of the position of each hand: "fist-edgepalm".

- The patient was asked to change in an alternating fashion the position of each hand: "fist-palm".

- The patient was asked to generate as many words they could think of that started with the letter F in 1 minute. 


\section{Table 2: Magnetic resonance imaging data}

\begin{tabular}{|c|c|c|c|}
\hline Patient & Reason for MRI & MRI findings & PVWD \\
\hline 1 & Elevated prolactin & Normal & None \\
\hline 3 & Right facial pain, rule out mass & Partially empty sella & Mild \\
\hline 5 & Fever of unkown origin & Normal & None \\
\hline 6 & Altered mental status & Increased signal on $\mathrm{T} 2$ and FLAIR in right perisylvian area & None \\
\hline 7 & Rule out vertebrobasilar insufficiency & $\begin{array}{l}\text { Chronic infarcts in left thalamus, cerebellum bilaterally, cerebral } \\
\text { peduncles bilaterally, subacute strokes in perisylvian areas bilaterally }\end{array}$ & Mild \\
\hline 8 & Headaches & Normal & None \\
\hline 9 & Cerebral hemorrhage & Chronic-subacute hemorrhage in $\mathrm{R}$ thalamus & Severe \\
\hline 10 & Dementia & Mild involutional changes & None \\
\hline 11 & History of seizures & Normal & None \\
\hline 12 & Headaches, rule out mass & Bilateral punctate deep WM changes & Mild \\
\hline 13 & Rule out optic neuropathy & Normal & None \\
\hline 17 & Mental status changes & Involutional changes & Mild \\
\hline 18 & Stroke & $\begin{array}{l}\text { Severe PVWD, white matter signal abnormalities in left basal } \\
\text { ganglia and pons }\end{array}$ & Severe \\
\hline 19 & Rule out ischemic attack & Prominent ventricles and sylvian fissures & Mild \\
\hline 20 & Pituitary mass $\mathrm{s} / \mathrm{p}$ bromocriptine treatment & Sellar mass $4.5 \times 3.5 \times 3.1 \mathrm{~cm}$ & Mild \\
\hline 21 & Headaches, rule out breast cancer metastases & Diffuse enhancement of meninges with nodularity & None \\
\hline \multirow[t]{2}{*}{22} & $\mathrm{~s} / \mathrm{p}$ inverted papilloma removal from & & \\
\hline & right sinus, right maxillectomy & Normal & None \\
\hline 23 & Evaluate left orbit & $8 \mathrm{~mm} \times 10 \mathrm{~mm}$ enhancing mass in left orbit & Mild \\
\hline 24 & History of multiple sclerosis & Moderate PVWD & Moderate \\
\hline 25 & Forgetfulness & Involutional changes & Moderate \\
\hline 33 & New onset seizure & Normal & None \\
\hline 34 & Rule out occipital lesion & Normal & None \\
\hline 35 & History of multiple sclerosis & Involutional changes & Mild \\
\hline 36 & Stroke work up & Left thalamic lacune & None \\
\hline 37 & History of multiple sclerosis & Mild PVWD & Mild \\
\hline 38 & Headaches & Normal & None \\
\hline 39 & Seizure work up & Normal & None \\
\hline 40 & Rule out aneurysm & Normal & None \\
\hline 41 & Brainstem meningioma & Large enhancing mass along clivus & Severe \\
\hline 42 & Rule out stroke & Normal & None \\
\hline 43 & History of multiple sclerosis & Severe PVWD & Severe \\
\hline 44 & History of multiple sclerosis & Normal & None \\
\hline 45 & History of sarcoid, look at orbits & None & Normal \\
\hline 46 & Tremor & Mild PVWD & Mild \\
\hline 47 & Rule out multiple sclerosis & Moderate PVWD & Moderate \\
\hline 48 & Rule out multiple sclerosis & Mild PVWD & Mild \\
\hline
\end{tabular}

Periventricular white matter disease (PVWD) 
Table 3: PVWD severity vs. Neurologic signs

\begin{tabular}{lccccc}
\hline Abnormalitites & None & Mild & Moderate & Severe & Total \\
visual tracking & 7 & 12 & 3 & 5 & 27 \\
paratonia-arms & 5 & 7 & 3 & 3 & 18 \\
3 step motor seq. & 2 & 7 & 2 & 5 & 16 \\
glabellar blink & 6 & 5 & 2 & 1 & 14 \\
suck reflex & 3 & 4 & 3 & 3 & 13 \\
paratonia-legs & 3 & 3 & 3 & 3 & 12 \\
nuchocephalic & 6 & 2 & 0 & 2 & 10 \\
lat gaze impers. & 2 & 2 & 2 & 4 & 10 \\
palmomental reflex & 4 & 4 & 1 & 1 & 10 \\
word fluency & 3 & 3 & 1 & 1 & 8 \\
palm/fist alt. & 1 & 2 & 0 & 2 & 5 \\
snout reflex & 0 & 2 & 3 & 0 & 5 \\
Ext to double stim. & 0 & 2 & 0 & 3 & 5 \\
grasp reflex & 0 & 0 & 2 & 2 & 4 \\
"world" backwards & 1 & 1 & 0 & 1 & 3 \\
conjugate gaze & 1 & 1 & 0 & 1 & 3 \\
impers eyes/tongue & 1 & 1 & 0 & 1 & 3 \\
TOTAL & 45 & 58 & 25 & 38 & 166 \\
& & & & & \\
\hline
\end{tabular}

prediction of PVWD with statistical significance were subject to further analysis using Spearman Rho correlations. Crosstabulations were performed to determine sensitivity and specificity.

\section{RESULTS}

Patients were referred for a MRI of the brain for various reasons. (Table 2). The reasons for ordering MRIs were limited to information found on the requisition. The MRI scans revealed 25 subjects without PVWD and 23 subjects with PVWD. Of the 23 subjects with PVWD, 13 had mild PVWD, five had moderate PVWD, and five had severe PVWD. Thirteen of the subjects with PVWD had no other MRI abnormality. Ten subjects with PVWD also had evidence of one of the following findings on MRI: involutional changes (6), a clival mass (1), a sellar mass (1), an area of enhancement: meninges (1), optic nerve (1). Of the 25 patients without PVWD, three had evidence of one of the following findings on MRI: involutional changes (1), an area of enhancement: meninges (1), optic nerves (1). One subject (without PVWD) had been treated with risperidone for a psychotic episode and had many cortical signs. Refer to Table 2 for more detail.

The number of abnormal neurologic tests in relation to severity of PVWD is shown in Table 3. The group with PVWD had more abnormal signs than the group without PVWD. The total number of neurologic signs correlated significantly (rho=0.67, p<0.001) with the severity rating of PVWD even when controlling for the effect of age $(r=0.51, p<0.001)$, but the correlation between age and PVWD severity was also significant (rho=0.54, $\mathrm{p}<0.001$ ).

The four signs that occurred with the greatest frequency in this study were interrupted horizontal visual tracking, paratonia in the arms, inability to perform a three step motor sequencing test, and a persistent glabellar reflex. A stepwise multiple regression analysis revealed two signs maximally predictive of PVWD: an abnormal three step motor sequencing test and interrupted horizontal visual tracking. The predictive relationship between these two neurologic signs and PVWD severity was independent of age.

Ninety-six per cent of the subjects with PVWD had one or both of these signs, and $64 \%$ of those subjects without PVWD had neither of these signs. Thirty-six per cent of the subjects without PVWD had one of those signs, though none had both. All of the subjects with severe PVWD had abnormal three step motor sequencing and interrupted horizontal visual tracking (Table 4). With two abnormal signs, the sensitivity for identifying PVWD on MRI is $92 \%$, the specificity is $100 \%$, and the positive predictive value is $100 \%$. The group with PVWD had more abnormal signs than the group without PVWD. Ninetyone percent of the subjects with PVWD had three or more abnormal tests, while $24 \%$ of the subjects without PVWD had three or more abnormal tests (Table 5). Jenkyn et $\mathrm{al}^{5}$ correlated three or more cortical signs with abnormalities on the HalsteadReitan neuropsychological test battery. Our findings are in agreement.

Table 4: PVWD severity vs. Neurologic signs

\begin{tabular}{lcccc}
\hline PVWD & $\begin{array}{c}\text { Abnormal 3 step } \\
\text { motor } \\
\text { sequencing only }\end{array}$ & $\begin{array}{c}\text { Abnormal } \\
\text { visual } \\
\text { tracking only }\end{array}$ & $\begin{array}{c}\text { Both } \\
\text { signs } \\
\text { present }\end{array}$ & $\begin{array}{c}\text { Neither } \\
\text { sign } \\
\text { present }\end{array}$ \\
none $\mathrm{n}=25$ & $2(8 \%)$ & $7(28 \%)$ & $0(0 \%)$ & $16(64 \%)$ \\
mild $\mathrm{n}=13$ & $1(8 \%)$ & $6(46 \%)$ & $6(46 \%)$ & $0(0 \%)$ \\
moderate $\mathrm{n}=5$ & $1(20 \%)$ & $2(40 \%)$ & $1(20 \%)$ & $1(20 \%)$ \\
severe $\mathrm{n}=5$ & $0(0 \%)$ & $0(0 \%)$ & $5(100 \%)$ & $0(0 \%)$
\end{tabular}

Table 5: Neurologic signs predict PVWD

\begin{tabular}{|c|c|c|c|}
\hline & $\begin{array}{c}\text { No PVWD } \\
n=25\end{array}$ & $\begin{array}{c}\text { PVWD } \\
\mathbf{n}=\mathbf{2 3}\end{array}$ & \\
\hline \#abnormal signs & 48 & 129 & $\mathrm{p}<0.01$ \\
\hline \#patients with abnormal 3 step & & & \\
\hline $\begin{array}{l}\text { motor sequencing } \\
\text { \#patients with abnormal }\end{array}$ & $2(8 \%)$ & $14(61 \%)$ & $\mathrm{p}<0.001$ \\
\hline $\begin{array}{l}\text { horizontal visual tracking } \\
\text { \#patients with one or both* }\end{array}$ & $7(28 \%)$ & $20(87 \%)$ & $\mathrm{p}<0.001$ \\
\hline abnormal signs & $9(36 \%)$ & $22(96 \%)$ & $\mathrm{p}<0.001$ \\
\hline \#patients with both* & & & \\
\hline abnormal signs & $0(0 \%)$ & $12(52 \%)$ & $\mathrm{p}<0.001$ \\
\hline $\begin{array}{l}\text { \#patients with } 3 \text { or more } \\
\text { abnormal signs }\end{array}$ & $6(24 \%)$ & $21(91 \%)$ & $\mathrm{p}<0.001$ \\
\hline
\end{tabular}

*abnormal 3 step motor sequencing and visual tracking 


\section{Discussion}

Hachinski et a ${ }^{10}$ coined the term leukoaraiosis to characterize the PVWD that is so often seen on computed tomography and MRI, especially in older patients. The development of the FLAIR technique has vastly improved our ability to detect PVWD. ${ }^{11}$

There has been some difference of opinion concerning the clinical significance of PVWD. ${ }^{12-16}$ It is associated with increasing age, ${ }^{17}$ dementing disorders, ${ }^{3}$ cardiovascular risk factors, ${ }^{17,18}$ ischemic injury, ${ }^{11}$ an increased risk of cerebrovascular events, ${ }^{17,19}$ and a higher risk of death from such events in older patients. ${ }^{20}$ Periventricular white matter disease is an independent risk factor for intracerebral hemorrhage in patients being anticoagulated. ${ }^{21,22}$ Severe PVWD is a major predictive factor for pneumonia, falls and death in the elderly population. ${ }^{23}$ Patients with PVWD, without focal or lateralized neurological signs or symptoms, often have incontinence, gait disorders, and difficulties carrying out activities of daily living. ${ }^{24}$

The presence of a combination of abnormal neurologic signs correlates with the presence and the severity of PVWD. Ninetyone percent of the subjects with PVWD had three or more abnormal signs from the battery of tests that was administered. In particular, the presence of either interrupted horizontal visual tracking and/or failing the three step motor sequencing test correctly classified $96 \%$ of subjects found to have PVWD. Although age contributed to this relationship, the correlation remained significant when age was eliminated as a variable.

Jenkyn et $\mathrm{al}^{5}$ found that certain clinical signs such as the nuchocephalic reflex, persistent glabellar blink and the suck reflex are more predictive than others for identifying abnormalities on the Halstead-Reitan battery of neuropsychological tests. These signs tend to increase in prevalence as individuals age ${ }^{6}$ but cortical dysfunction increases with age as well.

Some have de-emphasized the importance of PVWD claiming that it exists to varying degrees in both normal and demented elderly individuals. ${ }^{15,16}$ However, the findings from this study reinforce the concept that older subjects with PVWD are not normal. ${ }^{9,15}$

We found that two tests were especially sensitive as correlates of PVWD: visual tracking and three-step motor sequences. The reason for this is not obvious. Perhaps tests that require the participation of large cortical segments are especially affected by PVWD.

The correspondence of a structural change on MRI with a functional disturbance on neurological examination validates both the finding of PVWD on MRI and the neurological examination. Both abnormalities can be seen in younger individuals and neither is exclusively the result of aging. The correlation between MRI and clinical testing indicates that both PVWD and what some still regard as minor or soft neurologic signs are, independently, reliable indices of brain dysfunction. The sensitivity of having an abnormal three step motor sequencing test and interrupted horizontal tracking is $92 \%$, and the specificity is high as well. No one without PVWD on MRI had both of these signs.

A brain MRI that does not reveal PVWD does not mean the brain is normal. For example, epileptics and patients on neuroleptics typically do not have PVWD or any other MRI abnormalities. The subjects examined in this study were suspected of having some form of brain disease, hence they were referred for the MRI. The subjects with cortical signs on physical examination whose MRIs were normal may well have had any number of cerebral disorders that MRI cannot detect. The battery of 17 neurologic tests may be quite sensitive for revealing problems with brain functioning, for no subject with PVWD was free of abnormal cortical signs. It was not practical to spend a full day performing the Halstead-Reitan battery on this population because it can cost more than a MRI of the brain, and takes an entire day to complete. However, Jenkyn et al ${ }^{5}$ essentially used the same tests that were assessed in this study. They found a good correlation of cortical abnormalities with impairment on this neurological battery. The number of subjects in this study was small but the results encourage further investigation with a larger cohort into the relationship between findings on the neurological examination and findings on MRI scans.

Our finding that simple neurologic tests can predict the presence or absence of PVWD on MRI may have important clinical implications. The integration of the three step motor sequencing test and horizontal tracking adds approximately 20 seconds to a neurological examination. If patients have difficulty with these two tests, it is highly likely that they have some degree of PVWD. Even though PVWD is often present in older patients, these two tests could help prioritize patients who need a MRI of the brain. For example, a patient with abnormalities with these two tests in the setting of an otherwise nonfocal neurological examination may benefit from a MRI of the brain, since leukoaraiosis is associated with a higher risk of cerebrovascular events. Another situation in which a MRI may affect management is when a decision needs to be made regarding the initiation of anticoagulation, as leukoaraiosis is an independent risk factor for intracerebral hemorrhage.

The neurologic testing reported here is significant as proven by the correlation of three or more positive findings with MRI abnormalities. There is a strong correlation between abnormalities with the three step motor sequencing and horizontal tracking tests and the presence of PVWD on MRI. The fact that abnormalities on the neurologic exam are more prevalent amongst the aged also supports the significance of the findings, as neurologic impairment is more prevalent amongst the aged. Jenkyn et $\mathrm{al}^{5}$ showed that findings that many still refer to as "soft" or "unreliable" correlated with abnormalities on the Halstead-Reitan Battery. The findings of Jenkyn et $\mathrm{al}^{5}$ and our findings that correlate such signs with MRI abnormalities indicate that the neurological examination that we have performed reveals "hard" findings or reliable evidence of real neurologic impairment. Sometimes this impairment is the result of structural disease (leukoariosis), sometimes it is the result of a drug effect (risperidone). There are many other causes of frontal cortical and subcortical dysfunction. It is important to note that the neurological examination that can be performed at the bedside is one of several tests that can reveal the presence of neurologic dysfunction.

\section{ACKNOWLEDGEMENTS}

The authors thank Bolivia Davis, Gary Kay, Mary Quig and Jeffery Wilken for their assistance in the preparation of this paper. 


\section{REFERENCES}

1. Junque C, Pujol J, Vendrell $\mathrm{P}$, et al. Leuko-araiosis on magnetic resonance imaging and speed of mental processing. Arch Neurol 1990; 47:151-156.

2. Amar K, Bucks RS, Lewis T, Scott M, Wilcock GK. The effect of white matter low attenuation on cognitive performance in dementia of the Alzheimer type. Age Ageing 1996; 25:443-448.

3. Steingart A, Hachinski VC, Lau C, et al. Cognitive and neurologic findings in demented patients with diffuse white matter lucencies on computed tomographic scan (leukoaraiosis). Arch Neurol 1987; 44:36-39.

4. Kertesz A, Polk M, Carr T. Cognition and white matter changes on magnetic resonance imaging in dementia. Arch Neurol 1990; 47:387-391.

5. Jenkyn LR, Walsh DB, Culver CM, Reeves AG. Clinical signs in diffuse cerebral dysfunction. J Neurol Neurosurg Psychiatry 1977; 40:956-966.

6. Jenkyn LR, Reeves AG, Warren T, et al. Neurologic signs in senescence. Arch Neurol 1985; 42:1154-1157.

7. Luria AR. Higher Cortical Functions in Man. New York: Basic Books, Inc., 1966:330-333.

8. Borkowski JG, Benton AL, Spreen O. Word fluency and brain damage. Neuropsychologia 1967; 5:135-140.

9. Ylikoski RY, Ylikoski A, Erkinjuntti T, et al. White matter changes in healthy elderly persons correlate with attention and speed of mental processing. Arch Neurol 1993; 50:824-828.

10. Hachinski VC, Potter P, Merskey H. Leuko-Araiosis. Arch Neurol 1987; 44:21-23.

11. Pantoni L, Garcia JH. Pathogenesis of leukoaraiosis. Stroke 1997; 28:652-659.

12. Kozachuk WE, DeCarli C, Schapiro MB, et al. White matter hyperintensities in dementia of Alzheimer's type and in healthy subjects without cerebrovascular risk factors. Arch Neurol 1990; 47:1306-1310.
13. Mirsen TR, Lee DH, Wong CJ, et al. Clinical correlates of whitematter changes on magnetic resonance imaging scans of the brain. Arch Neurol 1991; 48:1015-1021.

14. Hunt AL, Orrison WW, Yeo RA, et al. Clinical significance of MRI white matter lesions in the elderly. Neurology 1989; 39:14701474.

15. Kobari M, Meyer JS, Ichijo M. Leuko-araiosis, cerebral atrophy, and cerebral perfusion in normal aging. Arch Neurol 1990; 47:161-165.

16. Fazekas F, Chawluk JB, Alavi A, Hurtig HI, Zimmerman RA. MR signal abnormalities at $1.5 \mathrm{~T}$ in Alzheimer's dementia and normal aging. AJNR Am J Neuroradiol 1987; 8:421-426.

17. Pantoni L, Garcia JH. The significance of cerebral white matter abnormalities 100 years after Binswanger's report. Stroke 1995; 26:1293-1301.

18. Breteler MMB, van Swieten JC, Bots ML, et al. Cerebral white matter lesions, vascular risk factors, and cognitive function in a population-based study: the Rotterdam Study. Neurology 1994; 44:1246-1252.

19. Streifer JY, Eliasziw M, Benavente OR, et al. Prognostic importance of leukoaraiosis in patients with symptomatic internal carotid artery stenosis. Stroke 2002; 33: 1651-1655.

20. Inzitari D, Cadelo M, Marranci ML, Pracucci G, Pantoni L. Vascular deaths in elderly neurological patients with leukoaraiosis. J Neurol Neurosurg Psychiatry 1997; 62:177-181.

21. Gorter JW. Major bleeding during anticoagulation after cerebral ischemia. Neurology 1999; 53:1319-1327.

22. Smith EE, Rosand J, Knudsen KA, et al. Leukoaraiosis is associated with warfarin-related hemorrhage following ischemic stroke. Neurology 2002; 59:193-197.

23. Briley DP, Haroon S, Sergent SM, Thomas S. Does leukoaraiosis predict morbidity and mortality? Neurology 2000; 54:90-94.

24. Tarvonen-Schroder S, Roytta M, Raiha I, et al. Clinical features of leuko-araiosis. J Neurol Neurosurg Psychiatry 1996; 60:431-436. 